within the plant's cells and by acting on their walls in some way determine the occurrence and direction of the plant's growth. In a later section Edwards and Gray of Atlanta, Georgia, give a valuable account of the intracellular changes observed to occur when plants are exposed to chronic acceleratory forces up to $150 \mathrm{~g}$. Some of the findings are considered to support the view that the amyloplast granules of plant cells act as gravity receptors.

In the absence of structurally definable nervous or receptor elements large gaps in the argument remain to be filled. Here the evidence relating to the action of the hormone auxin and other growth regulating substances is highly relevant and the contribution of Wilkins of Glasgow is of much interest.

It seems right to say that all who concern themselves with gravity and its effects on living organisms will owe much to the organizers of this symposium. The publication of its records in the form of this book is a notable achievement in the dissemination of scientific knowledge.

\section{S. Hallpike}

\section{Ions and Membranes}

Ion Transport and Membranes-A Biophysical Outline. By A. B. Hope. Pp. 121. (Butterworth: London, March 1971.) £3.00.

THE content of this book is not a great deal more than often found in a review article. It consists of just over a hundred pages which make up ten short and concise chapters. Although the text is limited it does adequately cover the basic theoretical concepts and experimental approaches which are currently associated with membrane studies of both plant and animal tissue. In fact the comparison between the properties of plant and animal membranes is an unusual and particularly valuable feature of this book.

The first chapter is concerned with the derivation of well established equations describing the distribution and passage of ions across membranes, including the relationships derived from the general flux equation such as the Goldman expressions. The use of irreversible thermodynamics for theoretical analyses of interactions between membrane fluxes is the subject of the second chapter. Only an elementary introduction is given but it is sufficient to give the reader an insight into the possible applications of this branch of thermodynamics to understanding the nature of solute and water fluxes in biological systems.

In the following chapters the author has attempted, where possible, to use much of the theory given in the earlier part of the book for quantitative analyses of experimental observations both with artificial and biological membranes. Two chapters discuss evidence for active ion transport processes in plant and animal cells and their dependence on cell metabolism. As well as outlining present biochemical knowledge of cation pumps in animal and plant tissue there is some discussion into the possible mechanism for light induced chloride fluxes in plant cells.

Other chapters briefly discuss the electrical characteristics of plant and animal membranes with reference to excitability and correlation of ionic fluxes with measured conductances. There is also a short but useful chapter on the properties of various types of artificial membranes.

Provided this book is used in conjunction with a reasonably detailed lecture course, I would thoroughly recommend it for specialized undergraduate and postgraduate studies. I also think that the author has produced a book which will be particularly valuable as a source of reference for plant and animal physiologists who have research interests in this field of cellular function. Considering the length and nature of this book it is a great pity that the publishers could not produce it in a paperback form at half the present price.

\section{J. BARBER}

\section{Histones Reviewed}

Histones and Nucleohistones. Edited by D. M. P. Phillips. Pp. xii +305 . (Plenum: London and New York, 1971.) n.p.

THE editor of this recent addition to the very limited number of books devoted to the topic of histones and the enigma of their structure and function in the cell comes from a well known stable in the histone field, although individual chapters are written by authors from several countries. The balance between structure and function is well maintained.

After an introductory chapter on preparation and characterization by E. W. Johns, giving a comprehensive survey of methods with a good coverage of references, we are launched into comparisons of the primary structures of histones and protamines by D. M.P. Phillips. Although this is the smallest chapter it will receive a great deal of attention in view of the current search for an explanation for the dramatic lack of species variation in the primary structures of histones. The author develops the theme of gene duplication to account for homology among histones as has been proposed for the protamines, and leaves one waiting eagerly for further information to become available. One criticism of this chapter is the confusing use of both the older three letter abbreviations for amino-acids and the more recent single letter code--we sometimes get one, sometimes the other and on occasion both, giving unnecessary duplication.

In the third chapter E. M. Bradbury and C. Crane-Robinson give an authoritative critical review of work on the conformation of histones and nucleohistones. This clearly indicates that ideas in this ficld have not gelled yet, and there is still scope for the brainwave to explain the interrelations between histone and nucleic acid and for the emergence of new techniques.

Unfortunately the authors do not define what they mean by nucleohistone here, for the acidic proteins of the cell nucleus get no mention or part to play. This contrasts with the next chapter by E. Fredericq on the chemical and physical properties of nucleohistones where the acidic proteins present come in for frequent comment in an established portrayal of properties of nucleohistones, collected together for critical appraisal.

It is, however, chiefly for the last two chapters, which constitute a third of the volume, on the functional aspects of chromatin, that the book will be bought and read avidly.

Histone biosynthesis is dealt with by Hnilica, McClure and Spelsberg, first in general terms and then in relation to embryogenesis and the gametes. Very little is left out, and with an up to date list of 282 references the reader feels that he is getting the total picture, including relationships with non-histone proteins.

The final chapter on functional aspects of DNA-associated proteins by Vincent Allfrey provides a lucid summary with 384 references. There are unanswered questions on all sides but this is the nature of the beast and the questions that should be asked become more apparent as the chapter progresses.

A minor irritation in the book is the use of independent chapter references, which entails the happy game of finding the end of the chapter if ever you want to check a reference. But the book is without doubt better than any of the few previous books on histones, giving both a good introduction to the subject and the latest state of the art; it will not become out of date too quickly.

\section{H. J. CRUFt}

\section{Terpenoids and Steroids}

Terpenoids and Steroids. Vol. 1. Senior Reporter K. H. Overton. Pp. xi+557. (The Chemical Society: London, July 1971.) $£ 11$.

THE aim of this volume is to provide detailed coverage of the literature on terpenoids and steroids from September 1969 to August 1970. It is the first of the 